\title{
BMJ Open Fostering student motivation towards community healthcare: a qualitative study
}

\author{
Shinsuke Yahata (D) , ${ }^{1}$ Taro Takeshima, ${ }^{2,3}$ Tsuneaki Kenzaka (D) , ${ }^{4}$ \\ Masanobu Okayama ${ }^{1}$
}

To cite: Yahata S, Takeshima T, Kenzaka T, et al. Fostering student motivation towards community healthcare: a qualitative study. BMJ Open 2021;11:e039344. doi:10.1136/ bmjopen-2020-039344

- Prepublication history and additional material for this paper is available online. To view these files, please visit the journal online (http://dx.doi.org/10. 1136/bmjopen-2020-039344).

Received 12 April 2020 Revised 18 November 2020 Accepted 30 November 2020

Check for updates

(C) Author(s) (or their employer(s)) 2021. Re-use permitted under CC BY-NC. No commercial re-use. See rights and permissions. Published by BMJ.

${ }^{1}$ Division of Community Medicine and Medical Education, Kobe University Graduate School of Medicine, Kobe, Japan

${ }^{2}$ Department of General Medicine, Shirakawa Satellite for Teaching and Research (STAR), Fukushima Medical University, Fukushima, Japan ${ }^{3}$ Center for Innovative Research for Communities and Clinical Excellence (CIRC2LE),

Fukushima Medical University,

Fukushima, Japan

${ }^{4}$ Division of Community

Medicine and Career

Development, Kobe University Graduate School of Medicine, Kobe, Japan

Correspondence to Dr Shinsuke Yahata; yahata-jci@umin.ac.jp

\section{ABSTRACT}

Objectives This study investigated what kinds of experiences influence regional quota (chiikiwaku) medical students' motivation to practice community healthcare (CH), and the mechanism of this influence, by focusing on their experiences in a community-based medical education (CBME) programme.

Design A qualitative thematic analysis based on interviews.

Setting Participants were recruited from the chiikiwaku students of Kobe University, Japan, using purposive sampling.

Participants Fourteen students participated. The median (IQR) age of participants was 23 (23-24); half were sixthyear and half fifth-year students.

Analysis From September to December 2018, the interviews were audiorecorded and transcribed verbatim. Data were analysed according to the 'Steps for Coding and Theorisation' method. Our theoretical framework comprised three internal motives (ie, needs, cognitions and emotions) and their subordinate motivation theories self-determination theory, expectancy-value theories, and positive and negative emotions, respectively.

Results Three mechanisms and corresponding experiences emerged. The first mechanism, envisioning and preparing for practising $\mathrm{CH}$, included corresponding experiences-empathy for the community, grasping the demands for $\mathrm{CH}$, understanding the practices of $\mathrm{CH}$, finding a role model and diminishing the conflicts between personal life and career. The second mechanism, belonging to a supportive community, included the robust construction of students' $\mathrm{CH}$ community and harmonisation with community residents. The third mechanism, psychological effects included the affect heuristic and framing effect. Student experiences brought about the changes and influences described in the presented mechanisms, and had both positive and negative impacts on their motivation towards $\mathrm{CH}$. These results can be interpreted through the multifaceted lenses of motivation theories.

Conclusions The authors revealed that motivation mechanisms of medical students towards $\mathrm{CH}$ derived from positive interaction with community residents, healthcare professionals and other students, and from exposure to attractive community environments and cultures. These experiences should be incorporated into CBME programmes to further encourage positive attitudes towards $\mathrm{CH}$.

\section{Strengths and limitations of this study}

- This study describes the motivation mechanisms of medical students towards practising community healthcare.

- It is unclear whether all medical students will be motivated to participate in community healthcare through similar mechanisms since the study focuses on a specific group of participants.

- Social desirability bias occurring through the relationship between teachers and students cannot be completely eliminated.

\section{INTRODUCTION}

Elderly patients with multimorbidity or irremediable diseases have been increasing in number as global populations age. ${ }^{1}$ Thus, the healthcare paradigm has shifted from conventional medical care, which cures diseases at hospitals, to community-based integrated care, which supports patients in the community. ${ }^{2}$ These social contexts demand nurturing healthcare professionals with insights into the concept of community healthcare $(\mathrm{CH})$, defined as the integration of health services and social care in the community, ${ }^{3}$ who can effectively manage integrated care systems. ${ }^{4}$

Furthermore, the uneven distribution of physician manpower is a serious global problem. WHO published global policy recommendations regarding access to health workers, ${ }^{5}$ which several countries have adopted to confront this challenge. The Japanese government has implemented a regional quota system (chiikiwaku) to manage this problem. ${ }^{6}$ Chiikiwaku allows medical students to receive prior benefits (eg, special entrance qualifications and scholarships) on the condition they work for a specified medical institution (especially in rural areas) for a certain period after graduation, during which they are required to practice $\mathrm{CH}$. In other words, they are required to become professionals who properly manage 
integrated care and compensate for the uneven distribution of doctors. However, it has been reported that the willingness of chiikiwaku students to remain in medically underserved areas declines from $52.3 \%$ to $19.2 \%$ during their studies. ${ }^{7}$ Withdrawal from the chiikiwaku system, which was reported to be about $10 \%$, is also a problem. ${ }^{8}$ Moreover, the preference for a primary care career, which is necessary for practising $\mathrm{CH}$, may decrease during medical school. ${ }^{9}{ }^{10}$ Therefore, it is necessary to continuously encourage chiikiwaku students, while they are undergraduates, to maintain and improve their motivation for practising $\mathrm{CH}$.

Numerous studies have demonstrated that communitybased medical education (CBME) programmes, which have been implemented worldwide, improve $\mathrm{CH}$ skills ${ }^{11-14}$ and increase motivation towards $\mathrm{CH}$, primary care and rural practice. ${ }^{11}{ }^{13-21}$ However, although the overall effectiveness of these programmes has been evaluated, and some educational components have been described, ${ }^{22} 23$ the knowledge of mechanisms that motivate students to participate in $\mathrm{CH}$ is insufficient. Elucidating these mechanisms can provide significant insights for designing and reconstructing CBME programmes to nurture future $\mathrm{CH}$ physicians. As such, our research objective is to investigate what kind of experiences influenced chiikiwaku students motivation for practising $\mathrm{CH}$ in CBME programmes and the mechanisms of this influence.

\section{METHODS}

\section{Qualitative approach and research paradigm}

We conducted a qualitative thematic analysis using interview data. The Standards for Reporting Qualitative Research ${ }^{24}$ was adopted for the presentation of our research. We chose the constructivism paradigm to interpret and understand the meanings of students' experiences. ${ }^{25}$ The constructivism paradigm asserts that people construct their understanding and knowledge of the world through experience and reflection on those experiences.

To interpret how students' experiences influenced their motivation for practising $\mathrm{CH}$, we used motivation theories as theoretical framework. There are numerous motivation theories; however, some confusion has arisen because of their conceptual overlaps and disagreements. ${ }^{26}$ In other words, there is no one theory that can absolutely explain human motivations. We chose to use Reeve's concept of three internal motives. ${ }^{27}$ Reeve defines 'motivation' as 'a condition inside us that desires a change' and proposes three internal motives for action: needs, cognitions and emotions. We considered 'student motivation towards CH' as 'a condition inside students that they desire to practice $\mathrm{CH}^{\prime}$ and adopted these three internal motives as a framework. In addition, in order to explain the three internal motives in detail, we used self-determination theory (SDT), ${ }^{28}$ expectancy-value theories (EVT), ${ }^{29}$ and positive and negative emotions ${ }^{30}$ as subordinate guiding theories. We chose SDT and EVT because they are current, widely recognised theories. ${ }^{2731-33}$ Emotions have been characterised as feeling-arousal-purposive-expressive phenomena, whose components cooperate in a complicated manner and allow us to react adaptively to the important events in our lives. ${ }^{26}$ For the purposes of our study, in order to express them more simply, we adopted six positive and six negative emotions. ${ }^{30}$

SDT, which is involved in needs, comprises three basic psychological needs: autonomy, competence and relatedness. ${ }^{28}$ The need for autonomy is a tendency to selforganise experiences and behaviours. The need for competence refers to a desire to affect the environment and attain valued outcomes. Finally, the need for relatedness is a tendency to love and care for and be loved and cared for by others. SDT also classifies the regulation types related to motivation: external, introjected, identified, integrated and intrinsic regulations. ${ }^{28}$ External regulation refers to the act of being controlled by external contingencies such as rewards or punishments. Introjected regulation refers to avoiding guilt or raising selfesteem by internalising external pressures. Identified regulation derives from the recognition and acceptance of the behaviour's importance. Integrated regulation refers to the act of integrating external identifications into other aspects of the self. In intrinsic regulation, the act itself becomes the purpose with a strong motivation. This regulation type leads to the most autonomous motivation.

EVT, which is involved in cognitions, consists of two important independent factors that influence behaviour: expectation of success and subjective task value. The expectation of success is the belief that one will succeed in one's tasks. The subjective task value comprises attainment value, utility value and cost. ${ }^{29}$

Regarding emotions, we defined six positive emotions as enthusiasm, cheerfulness, optimism, contentedness, calmness and relaxation, and negative emotions were tension, gloominess, depression, worry, miserableness and uneasiness. ${ }^{30}$ These frameworks were adopted to analyse the students' experiences and facilitate the interpretation of what their effects were on motivation and the mechanisms by which they operated. Using multiple theories encourages a deeper understanding of motivational principles. ${ }^{27}$

\section{Researcher characteristics and reflexivity}

As undergraduates, all researchers in this study were obligated students who then worked at rural medical institutions for 9 years postgraduation. Currently, they engage in community medicine education and research at the university while practising at rural medical institutions.

Additionally, SY and MO taught the research participants. Their hierarchical relationship ${ }^{34}$ could have resulted in the social desirability bias whereby students are motivated to respond in ways they think may be desirable to their teachers. ${ }^{35}$ To address this problem, requesting student participation, collecting data, and writing the transcripts were done only by SY. Although SY is a faculty 
member, SY has not been involved in the judgement of academic achievement and promotion of participating students. The coresearcher (MO) has been involved in the judgement of students, so he joined the analysis after students' personal identity information was deleted. We communicated this to the students and made an effort to create an atmosphere where they could relax and respond freely. The other coresearchers (TT and TK) were not involved in the research processes described above.

\section{Research context}

\section{Kobe University Chiikiwaku}

This research was conducted at Kobe University. Candidates who want to join Kobe University's chiikiwaku programme must receive recommendations from graduate high schools and then take the specific entrance examination. They can only apply to the programme before admission. After admission, they receive scholarships from the Hyogo prefectural government, which is responsible for securing medical care in Hyogo prefecture's rural areas. They have the obligation to work for 9 years postgraduation at rural medical institutions assigned by the prefectural government. These systems are common throughout Japan, with some differences. Chiikiwaku students comprise about $10 \%$ of all Kobe University medical students.

\section{Kobe University CBME}

All preclinical students, including chiikiwaku students, attend university $\mathrm{CH}$ lectures, programmes at nursing care facilities, and special needs schools. During their clinical years, they are exposed to home care, and a communitybased clerkship programme for about 2 weeks or 1 month is available. Additionally, certain special programmes are provided mainly for chiikiwaku students: a 2-day early exposure programme in rural community clinics, a 3-day summer programme in rural medical institutions, and a health education programme for the elderly in rural areas.

\section{Participants}

We used purposive sampling ${ }^{36}$ in order to focus on the mechanisms through which chiikiwaku students maintained and improved their motivation for practising $\mathrm{CH}$. We recruited fifth-year or sixth-year chiikiwaku students at Kobe University as research participants. We selected fifth-year or sixth-year students (ie, students in their clinical years) to effectively collect rich experiences related to $\mathrm{CH}$. There were 19 chiikiwaku students who satisfied the selection criteria. We continued sampling until obtaining saturation, that is, no further themes or constructs could be identified in the analysis. ${ }^{37}$

The first author (SY) emailed the first participant selected from the target groups that satisfied the selection criteria; then, if this student expressed an interest in participating, they were informed of the details in person and gave their written informed consent. After collecting and analysing their data, SY contacted the next participant in a similar manner.

\section{Data collection}

We chose individual, in-depth, semistructured interviews that allowed us to delve deeply into interviewees' experiences in order to acquire rich descriptions. ${ }^{25}$ Before the interviews, we prepared the interview guide, including eight questions based on the students' past practical CH-related experiences (see online supplemental appendix 1). The guide was intended to be revised but it was not necessary because of sufficient data. SY interviewed all study participants from September to December 2018. Each interview lasted about $60 \mathrm{~min}$ and was audiorecorded and then transcribed by SY.

There were 19 fifth-year or sixth-year chiikiwaku students (female $=10$, male $=9$ ) at Kobe University. Everyone who received the request kindly agreed to participate. Finally, a total of 14 students $(73.7 \%$; female $=9$, male $=5)$ participated (ie, saturation was reached after 14 students had been interviewed, at which point the interviews were concluded). Participants' median (IQR) age was 23 (23-24); half were fifth-year and the other half sixth-year students. Five participants subjectively recognised their hometown as rural and nine as urban.

\section{Data analysis}

The transcripts were analysed following the 'Steps for Coding and Theorisation' (SCAT) method, which is a grounded theory-inspired thematic analytical approach ${ }^{38}{ }^{39}$ SCAT consists of a four-step coding process. In the following, we describe the analytical approach by using examples provided by Otani. p. $36^{38}$

As a preliminary preparation, the text transcripts are segmented into fragmented data: 'The professor began to undress on the platform. Everyone was taken aback. Then, on his chest, an image of heart and blood vessels appeared. Everyone cheered and applauded.' In step 1, important words from the segmented text are extracted: 'professor,' 'image of heart and blood vessels appeared,' and 'cheered and applauded.' Step 2 consists of replacing the extracted word with operationalised words that represent the meaning extracts from step 1: 'authoritative teacher,' 'overlaying reality with teaching materials,' 'surprise teaching material presentation,' and 'students' surprise and pleasure.' In step 3, words from steps 1 and 2 are operationalised into codes representative for the context of the entire data: 'superimposition of real body and picture' and 'element of surprise.' Step 4 consists of creating themes and constructs; 'modelling reality,' 'layer presentation of reality and teaching materials,' and 'extracting motivation and expectations based on surprise.' Lastly, a storyline defined as latent meaning based on the themes from step 4, are written: 'this professor turned his body into a type of teaching material in a surprising way and realised a learning process that included surprises.' Finally, theories are 
generated based on the storyline: 'the use of one's body in medical education can leave a strong impression on learners.' Otani p. $159^{39}$ emphasise that the theories generated are 'not something that is universal and generally accepted, but what can be said from this data.'

The final themes were described by organising the theories that emerged through analysis. Otani stated that the characteristics of SCAT were as follows. The process of going back and forth between steps (1) and (4) and reading them repeatedly improves the quality and depth of the analyst's reflection, that is, improves reflexivity. Furthermore, the explicit description of the analytic process allowed the readers to replicate the result and disprove any errors, that is, improves falsifiability. ${ }^{38} \mathrm{We}$ chose this approach for its usability, process explicitness and improved reflexivity and falsifiability. These analysis processes were all done in Excel 2013 (Microsoft Corporation, Redmond, Washington, USA).

SY analysed the data in each step, and a coresearcher (MO) reviewed the transcripts and analysis results.

\section{Patient or public involvement}

This research was conducted with partial participant involvement. Participants were not invited to comment on the study design and methods. However, they were emailed their own transcripts and analysis results, and invited to comment on them. Four commented via email or face to face, and confirmed that there were no issues in the readability and accuracy of the transcripts and the results obtained from them. This process strengthened the overall credibility of the study. ${ }^{36}$

\section{RESULTS}

While exploring what kind of experiences influence chiikiwaku students' motivation for practising $\mathrm{CH}$ and the mechanisms of this influence, three mechanisms emerged as the main themes: envisioning and preparing for practising $\mathrm{CH}$, belonging to a supportive community and psychological effects. The corresponding experiences, which emerged as subthemes, brought about the changes and influences described in the presented mechanisms and had both a positive and negative impact on students' motivation towards $\mathrm{CH}$, depending on the level of fulfilment obtained through the experiences and whether students were able to accept them.

\section{Envisioning and preparing for practising $\mathrm{CH}$}

Chiikiwaku students envisioned and prepared for their future practice of $\mathrm{CH}$ through five experiences: 'empathy for the community,' 'grasping the demands for CH,' 'understanding the practices of $\mathrm{CH}$,' 'finding a role model,' and 'diminishing the conflicts between personal life and career.'

\section{Empathy for the community}

Students generated empathy by comparing their own thoughts, living environments, and cultural backgrounds with those of community residents and healthcare professionals through community dialogues and experiences.

I've been to many different areas... When I talk to local people, I can see their lives are not different from those in other areas. I think it's very important to listen to local people. (Student 5, rural)

This empathy results from the recognition that there is little difference between them. Even if there were some differences, they still felt empathy.

In certain areas I've visited, I heard I couldn't survive without a car. As my parents don't have a car, I could never imagine a life in which a car is indispensable. I understood what such a life is like when I went there...It may be simply that different people have different lifestyles. (Student 6, urban)

This empathy created a sense of familiarity and security in the community and reduced psychological barriers to continuing to belong to the community in the future.

\section{Grasping the demands for $\mathrm{CH}$}

Students saw that patients and their families appreciated healthcare professionals and directly experienced the community residents' expectations of the students. These experiences satisfied the needs of being evaluated by others, and evoked the willingness to commit to this demand in their future $\mathrm{CH}$ practice.

Every individual I saw expressed gratitude to the doctor...It was a good experience. I'm not sure if this will be my life's work, but I thought it would be nice to commit to this kind of work for a certain period. (Student 14, urban)

The residents were kind. I was impressed when they said to me, 'Please come back.' This experience made me feel that doctors like us are in demand. (Student 13 , rural)

Conversely, community residents' excessive expectations for students led to students' fears that they may not be able to fulfil them. This caused anxiety about future $\mathrm{CH}$ practices.

Of course, I would be glad...if I could actually save people's lives in the future. That being said, the pressure is too much, I wouldn't be able to do everything perfectly. Therefore... I feel it would be challenging. (Student 7, urban)

\section{Understanding the practices of $\mathrm{CH}$}

Students understood $\mathrm{CH}$ practices such as holistic medical care, comprehensive care, home care, preventive care and a community-oriented approach, then imagined their future practice. This experience enabled students to replace uncertainty about their own future practices with practical knowledge. Furthermore, if students were interested in these practices, the desire to practice these activities was stimulated. 
It goes without saying that I want to do this job. These experiences are really helpful in that I can now imagine how I would be working in the future. They were very effective opportunities because I could think about what I need to know. (Student 12, urban)

\section{Finding a role model}

If the students' role models' practices were deemed achievable for students in the future, their desire to emulate the role model was stimulated. This experience contributed to the formation of future self-images engaging in $\mathrm{CH}$.

The doctor was really...the best... He can be an ideal role model. I'm grateful I had many opportunities to see the doctor thereafter. I listened to many of his stories. (Student 5, rural)

However, this was obstructed if the students thought the role models' abilities were beyond their own capacities. Their anxiety about carrying out unfeasible practices in the future was stimulated.

I really admire them. I think they're great. On the other hand, I'm not confident I can be like them... There are a lot of genuinely smart doctors and those who are passionate about CH. If I was asked if I have such a strong passion, I don't have that much passion, so I'm worried if I can actually become a doctor like them. (Student 7, urban)

\section{Diminishing the conflicts between personal life and career}

Students felt a potential conflict between their imagined future private lives, including marriage and childcare, and their career ideals (eg, attaining specialist certifications). Diminishing this conflict secured the autonomy of their future daily lives and career choices.

I felt that life events like marriage and having a child will inevitably weaken motivation. That's why, having listened to Dr. A., I'm glad her talk helped me figure out how I can overcome such challenges. (Student 4, urban)

Specialist physician...I have been worried constantly because I don't know what to do if I became interested in obtaining certification. I mean, I thought I would be far behind if I continued as a chiikiwaku physician. However, I've heard chiikiwaku physicians have been able to obtain specialist certification... I appreciate this because I no longer have to be worried. (Student 4 , urban)

\section{Belonging to a supportive community}

Robust construction of students' $\mathrm{CH}$ community and harmonisation with community residents brought about a sense of belonging to a supportive community for chiikiwaku students.

\section{Robust construction of students' $\mathrm{CH}$ community}

The sense of belonging to the medical student community interested in $\mathrm{CH}$ was increased by constructing a robust community relationship.

Listening to different views and expectations of $\mathrm{CH}$ helps increase motivation. This is because through such experiences, I can feel first-hand that I am part of a group of people who take CH seriously. (Student 12 , urban)

On the other hand, critics of CH can decrease students' motivation. However, if the students' CH community functioned in a robust manner and students recognised their own sense of community belonging, then these conflicts might conversely strengthen their sense of belonging.

From time to time, I came across a doctor who unshakably believes in specialists. I didn't enjoy listening to such a doctor ... I would have a myopic view if I constantly listened to people who keep on saying that community physicians are better. I would rather like to say I have seen that side and I dare to have chosen this side. At that time, I felt uncomfortable. Though, in hindsight, that experience helped me choose the right path. (Student 1, urban)

Furthermore, the community support system made students feel secure. In this regard, students' affinity with the community of medical doctors had an interesting role. For some chiikiwaku students, their relationships with the local government's administrative department that has the authority to decide their future working location was perceived as an employee-employer relationship. However, when students realised there were doctors in the administrative department and that these doctors were involved in supporting their careers, the feeling of an employee-employer relationship was eased, and their feeling of autonomy regarding career choice was secured.

As the government always tells us where to go, I've been feeling that I'm made to work for them. As I didn't know that certain doctors are working as government officers, I was thinking that those who don't know much about what doctors do are unilaterally deciding what we should do. It was valuable to learn that the government includes those who understand doctors' work and that such people care about our careers and are trying to develop a system in which we can have equal opportunities. (Student 1, urban)

\section{Harmonisation with community residents}

As newcomers, students felt anxious about creating relationships with the community residents. However, as students recognised that they were accepted into the community, the sense of belonging to the community of residents was engendered. Furthermore, community residents' dedication to $\mathrm{CH}$ and medical education evoked students' desires to contribute to the community. 
As I was very welcomed there, I would like to give back to them by working hard. ...When they said, 'Is there anything to learn from us?' and 'I would be more than happy to help you if it would be beneficial,' I felt that I was given such valuable opportunities to learn. (Student 10, urban)

\section{Psychological effects}

Psychological effects, namely the affect heuristic and framing effect, stimulated students' motivation to contribute to $\mathrm{CH}$, by improving their conceptual image of $\mathrm{CH}$.

\section{Affect heuristic}

This is a psychological effect in which emotions affect the judgement of things quickly and automatically. ${ }^{40} \mathrm{CBME}$ elements such as unique experiences in the community, interaction with others, enjoyable and relaxed practice environments, acquisition of fresh knowledge and skills, and finding a role model induced enjoyable, happy, and positive feelings in students. These positive feelings impacted their conceptual image of $\mathrm{CH}$.

For clinical clerkship in university, for example, I have to take training seriously, but the summer program was rather fun, a more harmonious training and hence was quite interesting. (Student 5, rural)

\section{Framing effect}

This is a cognitive bias in which a presentation of something creates a decision-making bias. ${ }^{41}$ Showing that $\mathrm{CH}$ professionals had an enjoyable work life and lifestyle, and describing how rewarding $\mathrm{CH}$ can be to students created a framing effect that $\mathrm{CH}$ was worthwhile. This affected students' conceptual image of $\mathrm{CH}$.

All doctors look happy there. Every time I go there, I'm reminded they all enjoy working there. Every doctor is thriving there. (Student 4, urban)

\section{DISCUSSION}

We explored what kind of experiences influence chiikiwaku students' motivation for practising $\mathrm{CH}$ and the mechanism of this influence. Three mechanisms (main themes) and corresponding experiences (subthemes) emerged. The first theme was envisioning and preparing for practising $\mathrm{CH}$. Its subthemes were empathy for the community, grasping the demands for $\mathrm{CH}$, understanding the practices of $\mathrm{CH}$, finding a role model and diminishing the conflicts between personal life and career. The second theme was belonging to a supportive community. Its subthemes included robust construction of students' CH community and harmonisation with community residents. The third theme included psychological effects. Its subthemes were the affect heuristic and framing effect. The corresponding experiences brought about the changes and influences on the students described in the presented mechanisms, and motivated them to practise $\mathrm{CH}$.

We used theoretical frameworks ${ }^{27-30}$ to interpret the process of how these experiences motivated students. The first mechanism, envisioning and preparing for practising $\mathrm{CH}$, strengthens the expectation of success and subjective task value $^{29}$ through self-images of future $\mathrm{CH}$ practice. In addition, each experience that led to envisioning and preparing for practising $\mathrm{CH}$ also included other motivating factors for students. Empathy for the community brings positive emotions such as optimism, calmness, and relaxation from familiarity and security, which influence intrinsic motivation. ${ }^{30}$ Furthermore, deeper knowledge of the region can building a self-image of living in the region through reducing psychological barriers, and increase expectation of success ${ }^{29}$ in living and practising $\mathrm{CH}$ in the region. With regard to grasping the demands for $\mathrm{CH}$, students can recognise the importance of $\mathrm{CH}$ from the gratitude shown to healthcare professionals and the expectations of the students expressed by community residents and patients. This experience makes students recognise the task value ${ }^{29}$ of $\mathrm{CH}$. Furthermore, the regulation types proposed by $\mathrm{SDT}^{28}$ can also be used to interpret these experiences. This is an example of introjected regulation if their practice of $\mathrm{CH}$ is praised by others, and identified regulation which refers to the recognition that $\mathrm{CH}$ is important. Through these regulations, students' need for competence can be stimulated. On the other hand, excessive expectations cause negative emotions for students (ie, anxiety), who fear that they may not have the required abilities or may not meet the expectations of residents and patients, and reduce their expectation of success. ${ }^{29}$ With regard to finding a role model, if a student's expectation that they can become like their role model increases, their need for competence is stimulated; by contrast, if the expectation of success decreases, the need for competence is stifled. ${ }^{28}$ Additionally, finding a role model evokes a positive emotion arising from the desire to be like the role model: enthusiasm. This positive emotion could bring more internalised regulation, ${ }^{30}$ specifically integrated regulation, which integrates the identification of the value of $\mathrm{CH}$ and students' self-beliefs, or intrinsic regulation related to students' strong interests. ${ }^{28}$ With regard to diminishing the conflicts between personal life and career, knowing how physicians practising $\mathrm{CH}$ deal with these conflicts and improving students' ability to cope can increase the expectation of success. ${ }^{29}$ Assurance of students' autonomy in career choice secure their need for autonomy. ${ }^{28}$ Moreover, confirmation of autonomy bring about a shift from negative (worry) to positive emotions (calmness)..$^{30}$

With reference to the second mechanism, belonging to a supportive community satisfies students' relatedness needs. ${ }^{28}$ In addition, regarding the robust construction of students' CH community, the fact that doctors working in the local government actively support students and reduce the sense of an employee-employer relationship brings positive emotions (calmness) ${ }^{30}$ for students, and 
secures their autonomy needs ${ }^{28}$ regarding their career choice. With regard to harmonisation with community residents, the active involvement of residents in student education arouses the students' needs for competence, ${ }^{28}$ stimulating their desire to contribute to the community. This could also stimulate integrated regulation, which goes beyond simple praise or recognition of importance. ${ }^{28}$

Regarding the third main theme, the affect heuristic and framing effects induce improvements in the students' image of CH. Positive emotions (enthusiasm, cheerfulness, optimism, contentedness, calmness and relaxation) are greatly involved in this. ${ }^{40}$ These positive emotions also promote intrinsic regulation, related to students' strong interests. ${ }^{30}$

In previous studies, broad practice scope, ${ }^{42-45}$ general practice ${ }^{46}$ specialty, ${ }^{42}{ }^{44}$ clinical skill, ${ }^{46}$ role models, ${ }^{4344} 4748$ work satisfaction, ${ }^{42} 49$ lifestyle, ${ }^{43} 444650$ exposure to different places, ${ }^{49}$ rural rotation, ${ }^{49}$ patient interaction $^{46}$ and social network ${ }^{47}$ have been listed as factors that increase the medical students' primary care and/or rural healthcare motivations. Our study's findings are consistent with these previous findings. For example, broad practice scope, general practice, specialty, clinical skill and work satisfaction would be included in understanding the practices of $\mathrm{CH}$. Lifestyle would be included in diminishing the conflicts between personal life and career. Exposure to different places, rural rotation, and patient interaction would be included in empathy for the community, grasping the demands for $\mathrm{CH}$ and harmonisation with community residents. Finally, social network would be included in robust construction of students' $\mathrm{CH}$ community and harmonisation with community residents. However, the novel significance of our study is that it includes detailed descriptions of how these factors (experiences) affected students' motivation and interprets the results through the lenses of multifaceted motivation theories. In addition, importantly, the influence of psychological effects on students' motivation was suggested.

\section{Lessons for CBME programming}

How should our results be used when designing and reconstructing CBME programmes so as to effectively foster students' motivation to become involved in $\mathrm{CH}$ ? We suggest five possible approaches.

First, there should be many opportunities to interact with community residents as well as patients. By interacting with them, students can learn more about the community and the region, understand appreciation for and expectations of healthcare professionals and students, construct relationships with the community of residents, and have enjoyable experiences that they cannot otherwise gain by working in hospitals.

Second, patients and community residents should be asked to share their appreciation for healthcare professionals and health-related concerns with students. Communicating gratitude and expectations to others is sometimes embarrassing. However, this is important for helping students easily grasp the demands for $\mathrm{CH}$.

Third, healthcare professionals should provide positive messages to students about why they continue their work, how they feel rewarded, what they enjoy in work and life, and how to deal with conflicts between their private lives and careers. These make it easier for students to perceive healthcare professionals as role models, and facilitate the student's vision of their future $\mathrm{CH}$ practice. Furthermore, the framing effect improves the student's conceptual image of $\mathrm{CH}$.

Fourth, there should be time for students to interact with each other and have an enjoyable leisure time. This would construct robust student relationships and generate pleasant memories, which would improve the students' conceptual image of $\mathrm{CH}$ through affect heuristics.

Fifth, there should be time to become familiar with the community environments and cultures. If these become enjoyable experiences for students, students would become attached to the community and region, have increased empathy for them, and their conceptual image of $\mathrm{CH}$ would again be improved through affect heuristics.

Incorporation of these items into CBME programmes may encourage students to maintain and improve their motivation for practising $\mathrm{CH}$.

\section{Limitations}

There were several limitations to our study.

First, this study focused on what kind of experiences influence chiikiwaku students' motivation for practising $\mathrm{CH}$, and the mechanism of this influence, and was not intended to provide reasons to motivate other students to participate in the chiikiwaku system or engage in $\mathrm{CH}$. In order to increase the number of physicians engaged in $\mathrm{CH}$, it is necessary to motivate not only chiikiwaku students but all other students as well. Further research targeting general students who have no $\mathrm{CH}$ obligations are needed.

Second, study participants were limited to chiikiwaku students from a single university. There are many variations in the chiikiwaku system, including selection methods, scholarship options, and working style after graduation, among others. Chiikiwaku doctors who graduate from Kobe University may work at small medical institutions in rural areas, but some chiikiwaku doctors who attended other universities may work after graduation at tertiary care medical institutions in the prefectures where their own universities were located. Thus, it is unclear whether all obligated students will be motivated to participate in $\mathrm{CH}$ through similar mechanisms. In this regard, further research targeting chiikiwaku students who belong to other universities is also needed.

Third, this study was conducted with students by their teachers. Thus, their hierarchical relationship could be a problem. ${ }^{34}$ To address this problem, we made various efforts as described in the Methods section, however, we cannot completely eliminate the social desirability bias. ${ }^{35}$ 


\section{CONCLUSIONS}

The chiikiwaku students developed a motivation to be involved in $\mathrm{CH}$ through self-images of their future $\mathrm{CH}$ practice and life (ie, envisioning and preparing for practising $\mathrm{CH}$ ); constructing a robust student $\mathrm{CH}$ community and harmonising with community residents (ie, belonging to a supportive community); and experiences generating positive emotions that improve their conceptual image of CH (psychological effects). Many of these mechanisms are generated by positive interaction with community residents, healthcare professionals and other students, and in exposure to attractive community environments and cultures. Thus, these experiences should be incorporated into CBME programmes to further encourage students' positive attitudes towards $\mathrm{CH}$.

Acknowledgements The authors wish to thank Editage (www.editage.com) for English language editing.

Contributors SY was chiefly responsible for the study design, acquisition, analysis and interpretation of the data and drafting of the manuscript. M0 contributed to the study design, analysis and interpretation of the data, and a critical revision of the manuscript. TT and TK contributed to the study design and the critical revision of the manuscript. All of the authors approved the final version of the manuscript.

Funding This study was supported by Grants-in-Aid for Scientific Research from the Japan Society for the Promotion of Science (JSPS KAKENHI grant number JP16K08870).

Competing interests The authors report no conflicts of interest. The authors alone are responsible for the content and writing of the article.

Patient consent for publication Not required.

Ethics approval The Institutional Review Board of Kobe University Graduate School of Medicine approved this study on 17 July 2018 (number 180087).

Provenance and peer review Not commissioned; externally peer reviewed.

Data availability statement Data are available on reasonable request. The data used and/or analysed during the current study are available from the corresponding author on reasonable request.

Supplemental material This content has been supplied by the author(s). It has not been vetted by BMJ Publishing Group Limited (BMJ) and may not have been peer-reviewed. Any opinions or recommendations discussed are solely those of the author(s) and are not endorsed by BMJ. BMJ disclaims all liability and responsibility arising from any reliance placed on the content. Where the content includes any translated material, BMJ does not warrant the accuracy and reliability of the translations (including but not limited to local regulations, clinical guidelines, terminology, drug names and drug dosages), and is not responsible for any error and/or omissions arising from translation and adaptation or otherwise.

Open access This is an open access article distributed in accordance with the Creative Commons Attribution Non Commercial (CC BY-NC 4.0) license, which permits others to distribute, remix, adapt, build upon this work non-commercially, and license their derivative works on different terms, provided the original work is properly cited, appropriate credit is given, any changes made indicated, and the use is non-commercial. See: http://creativecommons.org/licenses/by-nc/4.0/.

\section{ORCID iDs}

Shinsuke Yahata http://orcid.org/0000-0002-2504-3416

Tsuneaki Kenzaka http://orcid.org/0000-0002-3120-6605

\section{REFERENCES}

1 Marengoni A, Angleman S, Melis R, et al. Aging with multimorbidity: a systematic review of the literature. Ageing Res Rev 2011;10:430-9.

2 Tsutsui T. Implementation process and challenges for the community-based integrated care system in Japan. Int $J$ Integr Care 2014;14:e002.

3 World Health Organization Centre for Health Development (Kobe, Japan). A glossary of terms for community health care and services for older persons. Kobe: Japan: World Health Organization Centre for Health Development, 2004. https://apps.who.int/iris/handle/10665/ 68896

4 Kainuma M, Kikukawa M, Nagata M, et al. Competencies necessary for becoming a leader in the field of community medicine: a Japanese qualitative interview study. BMJ Open 2018;8:e020082.

5 World Health Organization. Increasing access to health workers in remote and rural areas through improved retention: global policy recommendations. Geneva, Switzerland: WHO Press, 2010.

6 Matsumoto M, Inoue K, Takeuchi K. Quality of care in Japan: an additional strategy. Lancet 2011;378:e17.

7 Kataoka Y, Takayashiki A, Sato M, et al. Japanese regional-quota medical students in their final year are less motivated to work in medically underserved areas than they were in their first year: a prospective observational study. Rural Remote Health 2018;18:4840.

8 Matsumoto M, Takeuchi K, Owaki T, et al. Results of physician licence examination and scholarship contract compliance by the graduates of regional quotas in Japanese medical schools: a nationwide cross-sectional survey. BMJ Open 2017;7:e019418.

9 Hearst N, Shore WB, Hudes ES, et al. Family practice bashing as perceived by students at a university medical center. Fam Med 1995;27:366-70.

10 Bowman MA, Haynes RA, Rivo ML, et al. Characteristics of medical students by level of interest in family practice. Fam Med 1996;28:713-9.

11 Barrett FA, Lipsky MS, Lutfiyya MN. The impact of rural training experiences on medical students: a critical review. Acad Med 2011;86:259-63.

12 Kelly L, ed. Community-based medical education: a teacher's handbook. London, England: Radcliffe Publishing, 2012.

13 Crampton PES, McLachlan JC, Illing JC. A systematic literature review of undergraduate clinical placements in underserved areas. Med Educ 2013:47:969-78.

14 Lee SWW, Clement N, Tang N, et al. The current provision of community-based teaching in UK medical schools: an online survey and systematic review. BMJ Open 2014;4:e005696.

15 Laven G, Wilkinson D. Rural doctors and rural backgrounds: how strong is the evidence? A systematic review. Aust $J$ Rural Health 2003:11:277-84.

16 Okayama M, Kajii E. Does community-based education increase students' motivation to practice community health care?--a cross sectional study. BMC Med Educ 2011;11:19.

17 Viscomi M, Larkins S, Gupta TS. Recruitment and retention of general practitioners in rural Canada and Australia: a review of the literature. Can J Rural Med 2013;18:13-23.

18 Pfarrwaller E, Sommer J, Chung C, et al. Impact of interventions to increase the proportion of medical students choosing a primary care career: a systematic review. J Gen Intern Med 2015;30:1349-58.

19 Strasser R, Worley P, Cristobal F, et al. Putting communities in the driver's seat: the realities of community-engaged medical education. Acad Med 2015;90:1466-70.

20 Budhathoki SS, Zwanikken PAC, Pokharel PK, et al. Factors influencing medical students' motivation to practise in rural areas in low-income and middle-income countries: a systematic review. BMJ Open 2017;7:e013501.

21 Johnson GE, Wright FC, Foster K. The impact of rural outreach programs on medical students' future rural intentions and working locations: a systematic review. BMC Med Educ 2018;18:196.

22 Crampton PES. Medical student learning during longitudinal clinical placements in under-served, deprived, community areas: a qualitative study. Doctoral theses. Durham: Durham University, 2015.

23 Dubé TV, Schinke RJ, Strasser R, et al. Transition processes through a longitudinal integrated clerkship: a qualitative study of medical students' experiences. Med Educ 2015;49:1028-37.

24 O'Brien BC, Harris IB, Beckman TJ, et al. Standards for reporting qualitative research: a synthesis of recommendations. Acad Med 2014;89:1245-51.

25 Denzin NK, Lincoln YS. The SAGE Handbook of qualitative research. 5th ed. Thousand Oaks, CA: SAGE Publications, 2017.

26 Cook DA, Artino AR. Motivation to learn: an overview of contemporary theories. Med Educ 2016;50:997-1014.

27 Reeve J. Understanding motivation and emotion. 7th ed. Hoboken, NJ: John Wiley \& Sons, 2018.

28 Deci EL, Ryan RM. The "what" and "why" of goal pursuits: human needs and the self-determination of behavior. Psychol Inq 2000;11:227-68.

29 Wigfield A, Eccles JS. Expectancy-Value theory of achievement motivation. Contemp Educ Psychol 2000;25:68-81.

30 Vandercammen L, Hofmans J, Theuns P. Relating specific emotions to intrinsic motivation: on the Moderating role of positive and negative emotion differentiation. PLoS One 2014;9:e115396-e96. 
31 Ten Cate TJ, Kusurkar RA, Williams GC. How self-determination theory can assist our understanding of the teaching and learning processes in medical education. AMEE guide No. 59. Med Teach 2011;33:961-73.

32 Kusurkar RA, Croiset G, Mann KV, et al. Have motivation theories guided the development and reform of medical education curricula? A review of the literature. Acad Med 2012;87:735-43.

33 Orsini C, Binnie VI, Wilson SL. Determinants and outcomes of motivation in health professions education: a systematic review based on self-determination theory. J Educ Eval Health Prof 2016;13:19.

34 Boet S, Sharma S, Goldman J, et al. Review article: medical education research: an overview of methods. Can J Anaesth 2012;59:159-70.

35 Nederhof AJ. Methods of coping with social desirability bias: a review. Eur J Soc Psychol 1985;15:263-80.

36 Polit DF, Beck CT. Nursing research: principles and methods. 7th ed. Philadelphia, PA: Lippincott Williams \& Wilkins, 2004.

37 Saunders B, Sim J, Kingstone T, et al. Saturation in qualitative research: exploring its conceptualization and operationalization. Qual Quant 2018;52:1893-907.

38 Otani T. "SCAT" A qualitative data analysis method by four-step coding: Easy startable and small scale data-applicable process of theorization. Bulletin of the Graduate School of Education and Human Development (Educational Sciences), Nagoya University 2007;54:27-44.

39 Otani T. Qualitative research series SCAT: steps for coding and Theorization-A qualitative data analysis methodology with explicit procedures that is easy to start and applicable to smaller data. Kansei Kougaku 2011;10:155-60.
40 Finucane ML, Alhakami A, Slovic $P$, et al. The affect heuristic in judgments of risks and benefits. J Behav Decis Mak 2000;13:1-17.

41 Tversky A, Kahneman D. The framing of decisions and the psychology of choice. Science 1981;211:453-8.

42 Dixon AS, Lam CL, Lam TP. Does a brief clerkship change Hong Kong medical students' ideas about general practice? Med Educ 2000;34:339-47.

43 Jordan J, Brown JB, Russell G. Choosing family medicine. what influences medical students? Can Fam Physician 2003:49:1131-7.

44 Scott I, Wright B, Brenneis F, et al. Why would I choose a career in family medicine?: reflections of medical students at 3 universities. Can Fam Physician 2007;53:1956-7.

45 Ohta R, Ryu Y, Katsube T, et al. Students' perceptions of general medicine following community-based medical education in rural Japan. J Gen Fam Med 2019;20:236-43.

46 Stagg P, Greenhill J, Worley PS. A new model to understand the career choice and practice location decisions of medical graduates. Rural Remote Health 2009;9:1245.

47 Roberts C, Daly M, Kumar K, et al. A longitudinal integrated placement and medical students' intentions to practise rurally. Med Educ 2012;46:179-91.

48 Kawamoto R, Uemoto A, Ninomiya D, et al. Characteristics of Japanese medical students associated with their intention for rural practice. Rural Remote Health 2015;15:3112.

49 Codsi M-P, Rodrigue R, Authier M, et al. Family medicine rotations and medical students' intention to pursue family medicine: descriptive study. Can Fam Physician 2019;65:e316-20.

50 Birden $\mathrm{HH}$, Wilson I. Rural placements are effective for teaching medicine in Australia: evaluation of a cohort of students studying in rural placements. Rural Remote Health 2012;12:2167. 